\title{
Moderating Effect of Social Capital on the Relationship Between HRM Practices and the Performance of Companies Listed on NSE
}

\author{
M. A. Diriye ${ }^{1}$ P. K'Obonyo ${ }^{1}$, M. Munjuri ${ }^{1} \&$ G. Wainaina ${ }^{2}$ \\ ${ }^{1}$ Department of Business Administration, School of Business, University of Nairobi, Nairobi, Kenya \\ ${ }^{2}$ Department of Management Science, School of Business, University of Nairobi, Nairobi, Kenya \\ Correspondence: M. A. Diriye, PHD Scholar, Department of Business Administration, School of Business, \\ University of Nairobi, Nairobi, Kenya.
}

Received: September 22, 2021

Accepted: October 18, 2021

Online Published: October 20, 2021

doi:10.5430/jms.v12n4p1

URL: https://doi.org/10.5430/jms.v12n4p1

\begin{abstract}
Accessibility to broader information sources as well as the advancement of the quality of information, relevance, and timeliness is facilitated by social capital. These circumstances pave the way for individuals to improve their knowledge by interacting with coworkers daily. The study's main objective was to establish the moderating effect of social capital on the relationship between HRM practices and the performance of companies listed on NSE. The research was guided by the social-capital theory. This research utilized a descriptive research design and applied the positivist approach. The population of the study included 65 companies listed on the Nairobi Stock Exchange (NSE), and it employed both primary and secondary data, with secondary data consisting of the financial indicator Return on Assets (ROA). Questionnaires were employed to gather primary data, and descriptive and inferential statistics were utilized to analyze the data. The method utilized was linear regression. According to the findings, social capital has a moderating influence on the link between HRM practice configurations and company success on the NSE. This study recommends that training and development efforts be consistent, and that research institutes guarantee that training provided to employees is relevant to their needs. As a result, they should undertake a training need analysis to determine the program's relevance to learners. Research institutes must also ensure that they have the best possible resources.
\end{abstract}

Keywords: social capital, HRM practices and performance of firms listed on the Nairobi Securities Exchange (NSE)

\section{Introduction}

Social capital is an asset that occurs in group dealings among persons, systems, and groups (Putnam, 2000). Bourdieu's (2005) characterized social capital as genuine or potential assets implanted in a powerful social network of organized relationships. In his conceptualization, the dynamic contribution of everything being equal, solidarity, and commitment are the fundamental parts of this network. Bourdieu (2005) conceptualized social capital by concentrating on two components: the network that comprises of social relationships, and the capital (social, social, economic) that the individuals from the network possess. Based on the foregoing, social capital is an asset made by the relationships among people and different types of social structures, for example, associations, networks, and social orders.

Social capital is esteem like different types of capital, for example, physical and human capital. Social capital, be that as it may, depends on social relations among people, while human capital depends on instruction, experience, and functional capacity. Then again, physical capital depends on progressively unmistakable resources, for example, hardware, instruments, or machines (Lin, 2001). Lin saw social capital as a capital like others and contended that social relations are the primary parts of social capital through which significant resources are accessible and open. Lin depicted social capital as "resources installed in a social structure that is gotten to or prepared in purposive actions" (2001). As indicated by Lin, social capital is a sort of interest in social relations made by people so as to get to and use substantial resources accessible in social networks.

Social capital improves better group correspondence; progressively proficient aggregate activity; upgraded frameworks and utilization of scholarly capital; and improved access to capitals (Adler \& Kwon 2002, Hansen 2002). Social capital has more extensive results, which incorporates the age of further social capital, upkeep of social union that contributes in a roundabout way to upgraded economic execution. The financial estimation of client relations is not any more undetectable than the market estimation of a house. Social capital has turned into a basic empowering agent 
of development. It speaks to the stock made when a network of associations build up the capacity to work in coordinated effort to advance shared profitable increase.

Social capital, by and large, characterized as the real and possible resources installed in affiliations among entertainers, is progressively observed as a huge indicator of the group and organizational execution (Adler \& Kwon 2002). At the large-scale level, social capital can influence economic implementation and the procedure of economic development and advancement. Social capital is a main driver and wellspring of administrative heuristics for making expanded impalpable resources esteem, subsuming a greater part of other elusive ideas. An association displaying incredible social capital would be viewed as one, where interior divisions are significantly interrelated, sharing a common vision and goal. The company would likewise display similar characteristics remotely, effectively framing fruitful coalitions and organization to enhance its general market execution.

Human interaction is a principal basis for structure social capital. It has likewise been contended that the human measurements represent in any event half of all intelligent capital incentive to an association (O'Donnell et al. 2006). Simon additionally recognizes the important job that social and behavioural measurements play in successful correspondences and consequently, organizational execution (Simon, 2001). Social capital encourages singular knowledge by sharing of data and such arranged learning upgrade execution. Especially in the knowledge-serious association, data sharing and trade upgrade collaboration and common responsibility driving association execution (Sparrow et al. 2001).

Social capital may diminish organizational expenses in a significant number of similar ways human capital does (Chadwick, 2010). By recognizing and overseeing a diverse type of social capital crosswise over representative groups inside the design, human resource practices can encourage the progression of familiarity inside the firm, which at last prompts the upper hand. The sequence of knowledge both inside and crosswise over firms is fundamental for advancement and constant reception, inspiring a progressively possible aggressive position (Alvesson, 2012).

\section{Research Problem}

Actively pursuing human resource management practices ensures that organizations will easily fill senior vacant roles that may arise when the firm expands, when they lose key employees or have promotion opportunities. Human resource management methods, according to Tettey (2016), are most effective when they are carried out in a methodical, intentional effort that is guided by a written, organization-wide statement of purpose and policy. According to Waleed (2011), senior executives are acutely aware that the organization's long-term viability is contingent on having the right people in the right locations at the right time. If a successor was suddenly required and none had been selected, the impact on organizational continuity would be disastrous.

Organizations in particular firms operating at NSE have been seen to adopt all the human resource practices while others have adopted none. Some of the practices include high involvement of the employees, commitment maximizers against the cost minimizers, and mass production as opposed flexible production (Toh, Morgeson \& Campion, 2008). In addition, the organizations have been seen to have a particular focus on various human resource functions which include development, selection, training, as well as compensation. All these functions and practices have been seen to have an effect on organization performance. Lin (2001) saw social capital as a capital like others and contended that social relations are the primary parts of social capital through which significant resources are accessible and open.

Boxall and Purcell (2008) states that human resource design empowers the organization to frame social systems wherein it places individuals and system into specific relationships. This social systems additionally structure an asset for communitarian information management, creation and trade and change of learning. According to Schuler and Jackson (2005), the organizational characteristics includes organizational culture, organizational structure and communication strategies. Organizational structure influences its actions in two different ways: it facilitates the standard working methods and schedules rest, and it also establishes the people that get the chance to participate where basic leadership processes, and the rate at which their standpoints influence the association's actions (Boxall \& Purcell, 2008).

The human resource function can make a crucial contribution in developing the key competencies in the institutions and individual employees that lead to high performance (Guest, 2011). However, configurations of human resource practices that are adopted by firms without proper strategies have affected robust institutional limitations and lead to deteriorated levels of administrative and proficient uniqueness, and further precisely it has affected performance in highly competitive industries. This is greatly influenced by the organizational structure or governance, which involves those activities in an organization that determines how information flows across the various levels of management (Alvesson, 2012). 
The human resource configurations effectiveness is affected by the weak social capital among most organizations in Kenya, as evidenced by a lack of knowledge sharing and knowledge hoarding. Social capital, by and large, characterized as the real and possible resources installed in affiliations among entertainers, is progressively observed as a huge indicator of the group and organizational execution (Adler \& Kwon 2002). Employee approaches and behaviours, high levels of absence and decreased productivity, low quality productions, and inefficiency in service provision are witnessed in companies listed on NSE (Mwaniki, 2016). Therefore, human resource practices combination must be married with not just the strategic objectives and market orientation of the organization, but also the organizational structure. The NSE 20 increased 21 points or 0.64 percent to 3,357 on Tuesday, June 12, 2014, from 3,336 in the earlier transaction period. Historically, the Kenya securities market (NSE 20) grasped an entirely season high of 5,499.64 in March of 2015 and a record low of 2,789.64 in January of 2017.

Many studies have been carried out on human resource configurations. Lee (2012) examined the effect of HRM on intellectual capital. The study targeted targeting 777 companies in the Australian biotechnology industry. The study used census sampling to select the sample size. The results showed that human resource configurations were all significantly related to intellectual capital and social capital. This study focused on biotechnology industry thus creating a gap which the current study wishes to fill by targeting firms listed under NSE. Current study will also relate human resource configurations, organizational characteristics and social capital to performance to further fill the gap. A total of 61 companies listed under NSE will form part of the present study.

Studies done by Sarwar et al. (2016) in Pakistan on HRM practices and organizational performance. The target population was employees in construction firms in Pakistan. Simple random sampling was used and a sample size of 315. Findings showed that human resource setup makes an intelligent and aggregate culture inside the association, that support organizational sanity and is emphatically and fundamentally identified with associations dimension of social capital, which is influential for upgrade of association performance. Study by Choudhury (2014) was conducted in a developed country whose findings cannot be applicable into the Kenyan context and thus a knowledge gap exists. Current study focuses on firms listed under the Nairobi securities exchange. The study will also target top managers in fims listed under the NSE using census sampling.

The research conducted by Sagwa et al. (2015) was focused on two variables, which were human resource management practices and overall performance of employees and thus the findings cannot be used for the comparison with the current study thus creating a knowledge gap that needs to be filled. Current study will be filling this gap by involving other aspects such as organizational characteristics and social capital. Sagwa et al. (2015) targeted 60 companies while present study will target 61 companies thus filling the gap on target population.

Sabine (2010) assessed human resource configurations, job performance and incentive to carry on working of elder employees in different job types and found that the development configurations and job performance were significantly related to motivation to continue to work. However, they did not centre on the settings of HRM practices, organizational characteristics, and social capital which is the focus of the current study. In addition, the study did not relate the variables to the aspect of performance thus the findings cannot be applied to the current study thus creating a knowledge gap. Therefore, the study strives to fill the research gap by responding to the question - what is the moderating effect of social capital on the relationship between HRM practices and the performance of companies listed on NSE?

\section{Theoretical Literature Review}

This study was based on Social Capital Theory. Social capital theory was proposed by Bourdieu and Coleman in 1983. The theory states that social relationship among resources can lead to the accumulation as well as dvelopement of human capital. With regard to the evolutionary terms social capital can be termed as any social relationship whose results is reproductive benefits. Bourdieu developed the aspect of social capital from the theory of praxis. The type of social capital developed is inclined into various social fields which in turn comprises of a social praxis of various actors (Schwingel 1995). It has been regarded that social capital cannot be seen to free standing. In the defining of social capital, Bourdieu (1983) stated that capital can be termed as the labout which is accumulated and which exist as a material or in an incorporated form. The accumaated form of capital has been seen to be labour intensive buts its worth since it results into profits and still grows while still being produced.

Capital in the society occurs in there differnet kinds which include social capital, economic capital, as well as cultural capital. The three kinds of capital are converted into one another through the use of transformational labour. Through economic capital various goods and services can be obtained while social commitement and social relations can be obtained from social capital. The three forms of capital have their significance in that the society comprises of groups that have different cultural, economic, and social capital at thir disposal. 
The theory is applicable to the current study in that it explain how capital is distributed amog various groups in the society. For instance the existence of capital in various scoail field occurs in different amounts depending on the requirement of a particular group. These capitals have different values and they serve different fucntions. How every capital develops in its respective field is depedent on the application in the various social groups in the society. The researcher will utilize the theory to explain how sciaal capital is related to various human rsource practices in the organizations and how this translates to the organization performance (Bourdieu 1983).

\section{Configurations of Human Resource Management Practices, Social Capital and Organizational Performance}

Information is noted by Adler and Kwon (2002) as the initial direct advantage of social capital. They said that accessibility to broader information sources as well as the advancement of the quality of information, relevance, and timeliness is facilitated by social capital. These circumstances pave the way for individuals to improve their knowledge by interacting with coworkers daily. Additionally, it was stated by Reed et al. (2006) that social relations could enhance the exceptional human capital value. They argued that a vibrant network of social connections might diminish the quantity of time and investment required for gathering information as well as can serving as a knowledge diffusion valuable conduit and transfer having experienced and trustworthy contributors from different areas.

It was resolved that firms' efforts in employing, mentoring, scheming work as well as Human resource practices configurations implementation might be required to not only focus on retention of workers function but also on the development of the ability to network, cooperate and to share information as well as knowledge (Subramaniam \& Youndt, 2005).

Human resource management practices configurations of firm likewise enhance the learning and innovation abilities of the firm. Those firms that are tangled in innovation processes repeatedly make use of exterior knowledge (Hansen, 2001). The assistance gotten from human capital as from social capital would immensely vary for an organization which chooses to move first or follow later in their industry sector, or those who hold a position in-between, since their resources need is different (Finney et al., 2008).

\section{Research Methodology}

\subsection{Research Philosophy}

Two different research philosophies in social sciences are the phenomenology and positivism. The phenomenological approach is mainly qualitative and emphases on the direct experience, where the researcher attempts to interpret experiences that are observed in the research phenomenon (Cooper and Schindler, 2008). Critics of this method contend that it is subjective, lacks sound theoretical foundation and does not relate to the scientific platform of social science research.

The positivist approach is mainly quantitative and value-free as it separates the researcher from the phenomenon being studied; hence, it is objective (Easterby-Smith et al., 2002). This study adopted the positivist approach because of its quantitative nature, theoretical anchorage and hypothesis testing. Positivism aims at finding causal relationships that explain the patterns of research findings to establish scientific theories (Robson, 2014). Positivism approach is based on impartiality, neutrality, assessment, and legitimacy of results, thus making it appropriate for adoption in this study.

\subsection{Research Design}

For this study, descriptive research design was used. This is because, hypotheses were tested using data collected from across many organizations/firms at one point in time. The research design intended for this research was descriptive cross-sectional design. Descriptive analysis involves a description of phenomena at that particular time. It allows for the approximations of the sizes of a populace that have similar features and helps in defining the strength or magnitude of the relationship between variables (Mugenda, 2003).

\subsection{Population of Study}

The population of this research was 65 companies listed by NSE in Kenya (NSE Handbook) and were studied.

\subsection{Data Collection}

This study used both primary and secondary data; secondary data included ROA as a financial indicator, and data was gathered from NSE and Capital Markets Authority financial reports. Primary data was gathered using a questionnaire that included a five-point Likert scale for each variable derived from a variety of sources of literature that looked at similar topics. The questionnaire had four sections which contained both open and closed questions. Close ended questions were appropriate for this study as they gave the respondents a chance to choose from the available options. The respondents of the study were top managers from 65 corporations listed by NSE 


\subsection{Reliability and Validity Tests}

The degree to which an evaluation tool produces consistent and reliable results is referred to as reliability. Orodho defines the degree to which a particular measurement technique delivers comparable findings over a number of trials (2014). The researcher employed the split-half reliability approach to determine the instrument's reliability. The test was divided into two halves and given to all of the participants in the pilot study, with each half being assessed individually. To assess the reliability, the scores from one half of the test were compared to the scores from the other half. The strategy was chosen because assessing dependability with two tests or having two test administrations is impractical or undesirable (because of limited time or money). Cronbach's alpha (0.7) was used to assess the instrument's item dependability.

\subsection{Data Analysis}

Data was analyzed using descriptive and inferential statistics, as well as three types of regressions: basic linear regression, stepwise regression, and multiple regression. However, many tests were performed before to the regression, including normality and linearity, normalcy, multicollinearity, and homogeneity

\section{Results and Discussion}

The response rate was 92.3 percent from the 60 respondent who returned the questionnaires out the 65 respondents. This rate of response was satisfactory for the analysis since the response rate of 50 percent is sufficient. It has been suggested that of 60 percent is acceptable, while 70 percent is generally excellent as indicated by the perspectives on Mugenda and Mugenda (2003) and Sanders, at al. (2007).

6.1 Social Capital and Human Resource Management Practices and the Performance of Companies Listed on Nairobi Securities Exchange

The third goal of the study was to determine the impact of social capital on the relationship between HRM practice configurations and company performance on the NSE, with the hypotheses being that organizational characteristics factors do not play a role in the relationship between HRM practice configurations and company performance on the NSE. Respondents were asked to score their degree of agreement or disagreement with the statements supplied on a Likert scale of 1 to 5 , with 1 equaling no extent, 2 equaling low extent, 3 equaling moderate extent, 4 equaling large extent, and 5 equaling very great extent.

Table 1. Social capital

\begin{tabular}{|c|c|c|}
\hline & Mean & $\begin{array}{l}\text { Std. } \\
\text { Deviation }\end{array}$ \\
\hline Social networks & 2.800 & 0.935 \\
\hline $\begin{array}{l}\text { There are a high density and number of social connections within and across the } \\
\text { organization and with external stakeholders }\end{array}$ & 3.017 & 1.066 \\
\hline $\begin{array}{l}\text { In my organization people feel that relationships are based on care and respect for } \\
\text { others }\end{array}$ & 3.400 & 1.182 \\
\hline $\begin{array}{l}\text { There is substantially horizontal or cross-departmental communication (flow of } \\
\text { information) existing in my organization }\end{array}$ & 3.550 & 1.080 \\
\hline $\begin{array}{l}\text { The decision-making structure mostly flat (rather than mostly top-down and } \\
\text { hierarchical }\end{array}$ & 3.983 & 1.396 \\
\hline Participation is encouraged & 3.283 & 1.151 \\
\hline In my organization people feel that their working environment is positive and friendly & 3.650 & 1.471 \\
\hline Average Mean & 3.383 & \\
\hline
\end{tabular}

As per the findings of the study, majority of the respondents indicated to a great extent that the decision-making structure mostly flat (rather than mostly top-down and hierarchical (mean=3.983; standard deviation $=1.396$ ), in their organization people feel that their working environment is positive and friendly (mean=3.650; standard deviation $=1.471$ ) and that there is substantially horizontal or cross-departmental communication (flow of information) existing in my organization (mean $=3.550$; standard deviation $=1.080$ ). Further, respondents indicated to a moderate extent that 
in their organization people feel that relationships are based on care and respect for others (mean=3.400; standard deviation =1.182) and that participation is encouraged (mean=3.283; standard deviation $=1.151$ ). In addition, respondents indicated to a low extent that there are a high density and number of social connections within and across the organization and with external stakeholders (mean=3.017; standard deviation $=1.066$ ) and social networks ( mean $=2.800$; standard deviation $=0.935$ ). This is an indication that at firms listed at NSE, decision-making structure is mostly flat (rather than mostly top-down and hierarchical, at firms listed at NSE people feel that their working environment is positive and friendly and that there is substantially horizontal or cross-departmental communication (flow of information) existing in my organization.

Table 2. Social support

\begin{tabular}{lll}
\hline & Mean & $\begin{array}{l}\text { Std. } \\
\text { Deviation }\end{array}$ \\
\hline The ideas and opinions of external stakeholders factor into decision-making & 3.100 & 1.037 \\
People in my organization demonstrate a willingness to take a risk in the face of an & 2.850 & 0.954 \\
uncertain outcome or in situations where relying on others is required by their actions. & & \\
In my organization people listen with attention to others and value all voices & 3.383 & 1.462 \\
In my organization people feel that their voices are being heard. & 3.417 & 1.488 \\
In my organization everyone attends all of the required meetings and participates fully & 3.600 & 0.995 \\
\hline Average & $\mathbf{3 . 2 7 0}$ & \\
\hline
\end{tabular}

Based on the study findings, majority of the respondents indicated to a moderate extent that in their organization everyone attends all of the required meetings and participates fully (mean=3.600; standard deviation $=0.995$ ), in their organization people feel that their voices are being heard (mean=3.417; standard deviation $=1.488$ ), in their organization people listen with attention to others and value all voices (mean $=3.383$; standard deviation $=1.462$ ) and that the ideas and opinions of external stakeholders factor into decision-making (mean=3.100; standard deviation $=1.037$ ). In addition, respondents indicated to a low extent that in their organization people demonstrate a willingness to take a risk in the face of an uncertain outcome or in situations where reliance on others is required (mean $=2.850$; standard deviation $=0.954$ ). This is an implication that in firms listed at NSE everyone attends all of the required meetings and participates fully, in firms listed at NSE people feel that their voices are being heard, in firms listed at NSE people listen with attention to others and value all voices and that the ideas and opinions of external stakeholders factor into decision-making.

Table 3. Social cohesion

\begin{tabular}{lll}
\hline & Mean & $\begin{array}{l}\text { Std. } \\
\text { Deviation }\end{array}$ \\
\hline Stakeholders regularly participate in processes and decision-making & 3.883 & 0.640 \\
People in my organization have demonstrated a willingness to put in the requisite time and & 4.433 & 0.945 \\
effort (e.g. participating, going the extra mile, volunteering, etc.) & & \\
In my organization meetings are inclusive & 3.933 & 0.660 \\
In my organization people show tolerance and ability to work comfortably in & 3.850 & 0.880 \\
uncertainty/ambiguity & & \\
In my organization people feel that there is a sense of equality throughout & 4.450 & 0.529 \\
In my organization there is a high level of collaboration and co-creation. & 4.133 & 0.873 \\
\hline
\end{tabular}

According to the findings of the study, the majority of respondents indicated that people in their organization feel that there is a sense of equality throughout (mean $=4.450$; standard deviation $=0.529$ ), and that people in their organization are willing to invest time and energy (e.g. participating, going the extra mile, volunteering, etc.) (mean=4.433; standard 
deviation $=0.945$ ). In addition, respondents indicated to a great extent that in their organization meetings are inclusive ( mean=3.933; standard deviation $=0.660$ ), stakeholders regularly participate in processes and decision-making (mean $=3.883$; standard deviation $=0.640$ ) and that in their organization people show tolerance and ability to work comfortably in uncertainty/ambiguity $($ mean $=3.850$; standard deviation $=0.880$ ). This indicates that firms in NSE-listed businesses have a strong feeling of egalitarianism, that people in NSE-listed firms are eager to devote time and energy (e.g. contributing, going the extra mile, volunteering, etc.), and that there is a high degree of cooperation and co-creation.

\subsection{Hypothesis Testing}

In order to test the moderating effect of social capital on the link between HRM practice configurations and company performance on the NSE. A linear multiple regression analysis was used to test the null hypothesis that social capital has no significant moderating influence on the association between HRM practice configurations and company performance on the NSE. To reflect the combined influence of those factors, a single score was generated as the product of HRM practice configurations and social capital. However, using straight multiplication to produce such a score ran the danger of increasing the multicollinearity between the variables. This would have an impact on the linear regression coefficients' approximation. As a result, the problem was solved by converting the scores for HRM practice configurations and social capital to a $\mathrm{Z}$ score with a mean of zero and a standard deviation of one. The interaction variable was created by multiplying the two standardized variables of HRM practice configurations and social capital, as shown in Table 4.

Table 4. Moderating influence of social capital on the relationship between configurations of HRM practices and performance

\section{(a.) Model Summary}

\begin{tabular}{|c|c|c|c|c|c|c|c|}
\hline \multicolumn{2}{|l|}{ Model } & \multicolumn{2}{|l|}{$\mathrm{R}$} & \multicolumn{2}{|r|}{ R Square } & \multicolumn{2}{|c|}{ Adjusted R Square } \\
\hline 1 & \multicolumn{3}{|c|}{$.774^{\mathrm{a}}$} & \multicolumn{2}{|r|}{.599} & \multicolumn{2}{|c|}{.589} \\
\hline 2 & \multicolumn{3}{|c|}{$.782^{b}$} & \multicolumn{2}{|r|}{.611} & \multicolumn{2}{|c|}{.591} \\
\hline 3 & \multicolumn{3}{|c|}{$.793^{\mathrm{c}}$} & \multicolumn{2}{|r|}{.628} & \multicolumn{2}{|c|}{.599} \\
\hline \multicolumn{8}{|c|}{ (b.) Goodness-of-Fit ANOVA } \\
\hline \multirow[t]{2}{*}{ Model } & & & Sum of Squares & df & Mean Square & $\bar{F}$ & Sig. \\
\hline & Regression & & 214.212 & 1 & 214.212 & 59.686 & $.000^{\mathrm{b}}$ \\
\hline \multirow[t]{2}{*}{1} & Residual & & 208.162 & 58 & 3.589 & & \\
\hline & Total & & 422.374 & 59 & & & \\
\hline \multirow{3}{*}{2} & Regression & & 218.741 & 2 & 109.370 & 30.680 & $.000^{\mathrm{c}}$ \\
\hline & Residual & & 203.205 & 57 & 3.565 & & \\
\hline & Total & & 421.946 & 59 & 109.370 & & \\
\hline \multirow{3}{*}{3} & Regression & & 224.755 & 3 & 74.918 & 21.403 & $.000^{\mathrm{d}}$ \\
\hline & Residual & & 196.000 & 56 & 3.500 & & \\
\hline & Total & & 420.755 & 59 & & & \\
\hline
\end{tabular}

(c.) Beta Coefficients

Unstandardized Coefficients $\begin{aligned} & \text { Standardized } \\ & \text { Coefficients }\end{aligned}$

\begin{tabular}{llcccc}
\cline { 3 - 5 } Model & B & Beta & T-value & Sig. \\
\hline \multirow{2}{*}{1} & 7.954 & & 5.034 & .000 \\
\cline { 2 - 5 } & $\begin{array}{l}\text { Configurations of HRM } \\
\text { practices }\end{array}$ & .589 & 0.774 & 7.726 & .000 \\
\hline
\end{tabular}




\begin{tabular}{|c|c|c|c|c|c|}
\hline \multirow{3}{*}{2} & (Constant) & 7.795 & & 4.931 & .000 \\
\hline & $\begin{array}{l}\text { Configurations of HRM } \\
\text { practices }\end{array}$ & .672 & .882 & 6.372 & .000 \\
\hline & Social capital & -.079 & -.156 & -1.127 & .267 \\
\hline \multirow{4}{*}{3} & (Constant) & .759 & & .136 & .893 \\
\hline & $\begin{array}{l}\text { Configurations of HRM } \\
\text { practices }\end{array}$ & 1.015 & 1.332 & 3.600 & .001 \\
\hline & Social capital & .415 & .820 & 1.083 & .286 \\
\hline & $\begin{array}{l}\text { Zscore(Configurations } \\
\text { of HRM practices } \mathrm{x} \\
\text { Social capital) }\end{array}$ & -.023 & -1.335 & -1.311 & .198 \\
\hline \multicolumn{6}{|c|}{ a. Dependent Variable: Performance } \\
\hline \multicolumn{6}{|c|}{ b. Predictors: (Constant), Configurations of HRM practices } \\
\hline \multicolumn{6}{|c|}{ c. Predictors: (Constant), Configurations of HRM practices, Social capital } \\
\hline
\end{tabular}

Table 4 above shows the linear regression results and from the third model, R Square was 0.628 meaning Social capital and HRM practice combinations accounted $31 \%$ of the difference in performance. Overall, the model was significant since the p-value was less than 0.05 , implying that social capital had a substantial moderating influence on the link between HRM practice configurations and company performance on the NSE. With respect to individual significance, both social capital and configurations of HRM practices were significant since p-values were less than 0.05 and the resulting prediction equation was performance $=1.015$ configurations of HRM practices +0.415 social capital and configurations of HRM practices had more impact on performance On interpretation, if social capital and configurations of HRM practices were increased by one unit, then performance would go up, on the average by 1.119, and 0.689 units, respectively.

Moderating Path Diagram

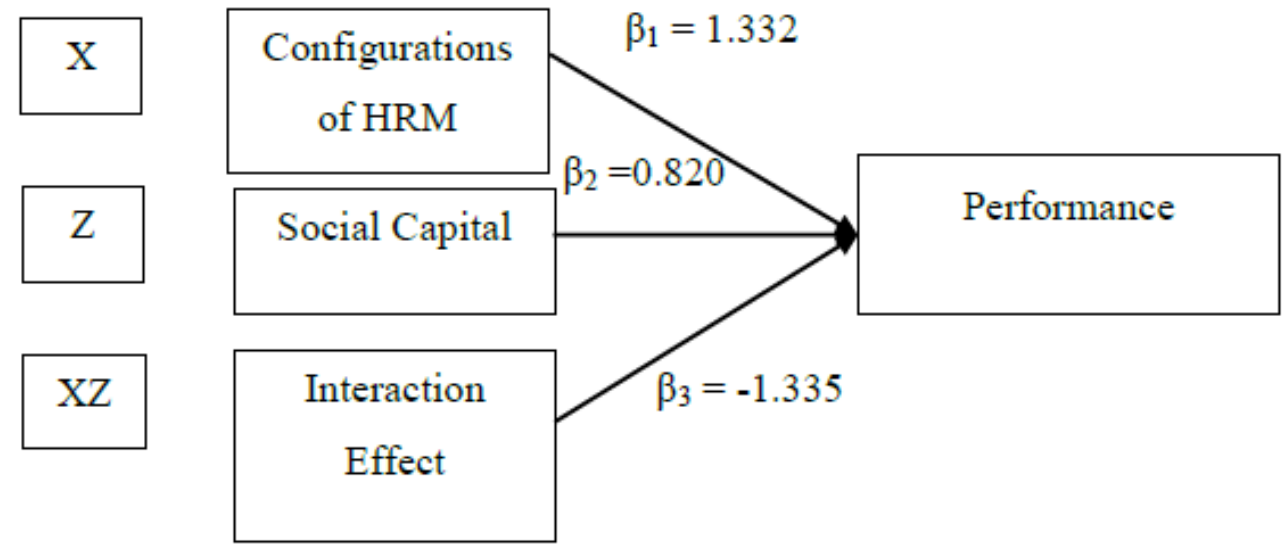

\subsection{Discussion of Findings}

According to the findings, social capital had a moderating effect on the relationship between HRM practice configurations and NSE performance. Reed et al. (2006) indicate, similar to the study findings, that social interactions can improve the unique human capital worth. They argued that a vibrant network of social connections might diminish 
the quantity of time and investment required for gathering information as well as can serving as a knowledge diffusion valuable conduit and transfer having experienced and trustworthy contributors from different areas. It was resolved that firms' efforts in employing, mentoring, scheming work as well as human resource practices configurations implementation might be required to not only focus on retention of workers function but also on the development of the ability to network, cooperate and to share information as well as knowledge (Subramaniam \& Youndt, 2005). The HRM practices configurations of firm likewise enhance the learning and innovation abilities of the firm. Those firms that are tangled in innovation processes repeatedly make use of exterior knowledge (Hansen, 2001).

\section{Conclusion and Recommendations}

The study also concludes that at firms listed at NSE, decision-making structure is mostly flat (rather than mostly top-down and hierarchical, at firms listed at NSE people feel that their working environment is positive and friendly and that there is substantially horizontal or cross-departmental communication (flow of information) existing in my organization. Also, the study concludes that in firms listed at NSE everyone attends all of the required meetings and participates fully, in firms listed at NSE people feel that their voices are being heard, in firms listed at NSE people listen with attention to others and value all voices and that the ideas and opinions of external stakeholders factor into decision-making. Further the study concludes that in firms listed at NSE people feel that there is a sense of equality throughout, at firms listed at NSE people demonstrate a willingness to invest time and energy (e.g. participating, going the extra mile, volunteering, etc.) and that there is a high level of collaboration and co-creation.

This study recommends that the organizations should put mechanisms in place to ensure that all stakeholders are aware of the organizations culture, structure and human reward practices so as to attract the best applicants.

The type of employees employed by the firm is determined by the recruitment and selection procedure. According to the findings of the study, consistency should be maintained in recruitment and selection activities. As a result, it is strongly suggested that the procedure be objective. As a result, job specifications should be written and adhered to as tightly as possible throughout the process. Having an interview panel that is professional and does not have any biases is also necessary. As a result, enterprises listed on the NSE should search for better methods of screening the panel, and if they choose to engage consultant firms for this purpose, they should choose organizations with a track record of integrity. Additionally, there should be experts in the various types of selection tests that will be conducted throughout the interview process included on the interview panel. Last but not least, research institutes should have well established recruitment policies that are compliant with the applicable laws and regulations.

\subsection{Suggestions for Further Study}

The study focused on the firms listed at the NSE and obtained results, which are useful in the Kenyan context. It would be useful for a replication of the study to be carried out in the next five years in order to confirm or refute the relationships between the variables. The mediating effect of HRM on organizational performance may also be investigated in future studies. A case study on a few major companies is recommended to facilitate collection of in-depth information.

\section{References}

Adler, P. S., \& Kwon, S. W. (2002). Social capital: Prospects for a new concept. Academy of Management Review, 27(1), 17-40. https://doi.org/10.2307/4134367

Alvesson, M. (2012). Critical leadership studies: The case for critical performativity. Human Relations, 65(3), 367-390. https://doi.org/10.1177/0018726711430555

Bourdieu, A. (2005). Social capital and development studies II: can Bourdieu travel to policy?. Progress in development studies, 7(2), 155-162. https://doi.org/10.1177/146499340600700205

Boxall, P., \& Purcell, J. (2008). Strategy and human resource management. Macmillan International Higher Education. https://doi.org/10.1093/oxfordhb/9780199547029.003.0001

Chadwick, C. (2010). Theoretical insights on the nature of performance synergies in human resource: Toward greater precision. Human Resource Management, 20, 85-101. https://doi.org/10.1016/j.hrmr.2009.06.001

Cooper, D., \& Schindler, P. (2008). International Edition: Business Research Methods.; New Delhi: MacGraw-Hill. Bulletin. District Development Report (2007). Ministry of Planning, Murang'a District, Kenya government District Development reports issue Bulletin.

Easterby-Smith, M., Li, S., \& Bartunek, J. (2002). Research methods for organizational learning: The transatlantic gap. Management Learning, 40(4), 439-447. https://doi.org/10.1177/1350507609339682 
Guest, D. E. (2011). Human resource management and performance: still searching for some answers. Human Resource Management Journal, 21(1), 3-13. https://doi.org/10.1111/j.1748-8583.2010.00164.x

Hansen, N. (2002). Completely derandomized self-adaptation in evolution strategies. Evolutionary Computation, 9(2), 159-195. https://doi.org/10.1162/106365601750190398

Lee, C. (2012). How does HRM enhance strategic capabilities? Evidence from the Korean management consulting industry. The International Journal of Human Resource Management, 23(1), 126-146. https://doi.org/10.1080/09585192.2011.561247

Lin, N. (2002). Social capital: A theory of social structure and action (Vol. 19). Cambridge University Press. https://doi.org/10.1017/CBO9780511815447

Mugenda, O., \& Mugenda, A. (2003). Research methods: quantitative and qualitative approaches.

Mwaniki, M. W. (2016). Modelling the Impacts of Predicted Environmental Change on the Frequency and Magnitude of Rainfall-Induced Landslides in Central Kenya.

Putnam, R. D. (2000). Bowling alone: America's declining social capital. In Culture and politics (pp. 223-234). Palgrave Macmillan, New York. https://doi.org/10.1007/978-1-349-62397-6_12

Robson, C. (2014). How to do a research project: a guide for undergraduate students. Wiley Global Education.

Sagwa, E. V., K’Obonyo, P., \& Ogutu, M. (2015). Human Resource Management Practices and Performance of Firms Listed on the Nairobi Securities Exchange.

Schuler, R. S., \& Jackson, S. E. (2005). A quarter-century review of human resource management in the US: The growth in importance of the international perspective. Management Revue, 11-35. https://doi.org/10.5771/0935-9915-2005-1-11

Toh, S. M., Morgeson, F. P., \& Campion, M. A. (2008). Human resource configurations: investigating fit with the organizational context. Journal of Applied Psychology, 93(4), 864. https://doi.org/10.1037/0021-9010.93.4.864

Waleed, A. (2011). The Relationship Between Human Resource Practices and Employee Retention In Public Organization: An Exploratory Study Conducted in the United Arab Emirates. Unpublished Thesis, Edith Cowan University.

\section{Copyrights}

Copyright for this article is retained by the author(s), with first publication rights granted to the journal.

This is an open-access article distributed under the terms and conditions of the Creative Commons Attribution license (http://creativecommons.org/licenses/by/4.0/). 